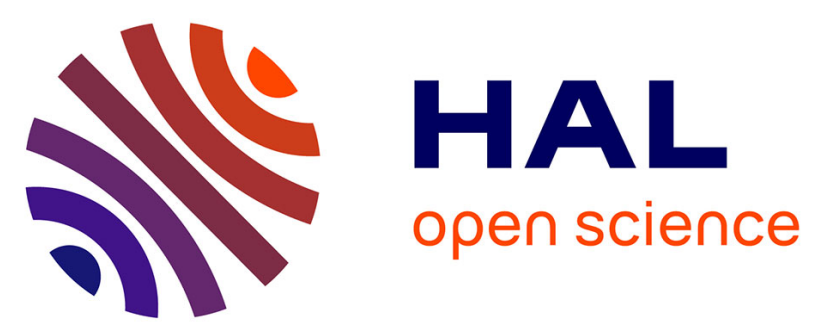

\title{
Bisphenol A induces steatosis in HepaRG cells using a model of perinatal exposure
}

Simon Bucher, Pégah Jalili, Dounia Le Guillou, Karima Begriche, Karine

Rondel, Sophie Martinais, Daniel Zalko, Anne Corlu, Marie-Anne Robin, Bernard Fromenty

\section{To cite this version:}

Simon Bucher, Pégah Jalili, Dounia Le Guillou, Karima Begriche, Karine Rondel, et al.. Bisphenol A induces steatosis in HepaRG cells using a model of perinatal exposure. Environmental Toxicology, 2017, 32 (3), pp.1024-1036. 10.1002/tox.22301 . hal-01470709

\section{HAL Id: hal-01470709 \\ https://hal-univ-rennes1.archives-ouvertes.fr/hal-01470709}

Submitted on 22 May 2017

HAL is a multi-disciplinary open access archive for the deposit and dissemination of scientific research documents, whether they are published or not. The documents may come from teaching and research institutions in France or abroad, or from public or private research centers.
L'archive ouverte pluridisciplinaire HAL, est destinée au dépôt et à la diffusion de documents scientifiques de niveau recherche, publiés ou non, émanant des établissements d'enseignement et de recherche français ou étrangers, des laboratoires publics ou privés. 
Bisphenol A induces steatosis in HepaRG cells using a model of perinatal exposure

Simon Bucher, ${ }^{1}$ Pégah Jalili, ${ }^{1}$ Dounia Le Guillou, ${ }^{1}$ Karima Begriche, ${ }^{1}$ Karine Rondel,${ }^{1}$ Sophie Martinais, ${ }^{1}$ Daniel Zalko, ${ }^{2}$ Anne Corlu, ${ }^{1}$ Marie-Anne Robin, ${ }^{1}$ Bernard Fromenty ${ }^{1}$

${ }^{1}$ INSERM, UMR991; Université de Rennes 1, Rennes, France

${ }^{2}$ UMR1331, TOXALIM (Research Centre in Food Toxicology), Institut National de la Recherche Agronomique (INRA); Université de Toulouse, Toulouse, France

Correspondence to: B. Fromenty; e-mail: bernard.fromenty@inserm.fr; tel: +33 2232330 44; fax: +33 223235385

Running title: Bisphenol A-induced steatosis in HepaRG cells

Conflict of interest: The authors declare that they have no conflicts of interest regarding this work. 
ABSTRACT: Human exposure to bisphenol A (BPA) could favor obesity and related metabolic disorders such as hepatic steatosis. Investigations in rodents have shown that these deleterious effects are observed not only when BPA is administered during the adult life but also with different protocols of perinatal exposure. Whether perinatal BPA exposure could pose a risk in human is currently unknown, and thus appropriate in vitro models could be important to tackle this major issue. Accordingly, we determined whether long-term BPA treatment could induce steatosis in human HepaRG cells by using a protocol mimicking perinatal exposure. To this end, the kinetics of expression of seven proteins differentially expressed during liver development was determined during a 4-week period of cell culture required for proliferation and differentiation. By analogy with data reported in rodents and humans, our results indicated that the period of cell culture around day 15 and day 18 after seeding could be considered as the "natal" period. Consequently, HepaRG cells were treated for 3 weeks with BPA (from 0.2 to $2000 \mathrm{nM}$ ), with a treatment starting during the proliferating period. BPA was able to induce steatosis with a non-monotonic dose response profile, with significant effects on neutral lipids and triglycerides observed for the $2 \mathrm{nM}$ concentration. However, the expression of many enzymes involved in lipid and carbohydrate homeostasis was unchanged in exposed HepaRG cells. The expression of other potential BPA targets and enzymes involved in BPA biotransformation was also determined, giving answers as well as new questions regarding the mechanisms of action of BPA. Hence, HepaRG cells provide a valuable model that can prove useful for the toxicological assessment of endocrine disruptors on hepatic metabolisms, in particular in the developing liver.

Keywords: bisphenol A; steatosis; HepaRG cells; perinatal exposure; lipids; xenobiotic-metabolizing enzymes; pregnane X receptor; UDP-glucuronosyltransferase; $\beta$-glucuronidase; cytochrome P450 


\section{INTRODUCTION}

Human exposure to the synthetic chemical bisphenol A (BPA) is suspected to favor obesity and related metabolic disorders such as insulin resistance, type 2 diabetes and non-alcoholic fatty liver disease (NAFLD) (Trasande et al., 2012; Khalil et al., 2014; Oppeneer and Robien, 2015; Rancière et al., 2015). NAFLD refers to a large spectrum of hepatic lesions including fatty liver (also referred to as hepatic steatosis), nonalcoholic steatohepatitis and cirrhosis. Actually, similarly to many other environmental contaminants, BPA might exert more harmful effects when exposure occurs during the perinatal period, or in the early postnatal years (Calkins and Devaskar, 2011; Rochester, 2013; Wei et al., 2014).

Although BPA-induced steatosis is likely a secondary consequence of higher body weight and associated metabolic disorders such as insulin resistance, other mechanism(s) could be involved as well. Indeed, several studies have demonstrated that BPA is able to induce lipid accumulation in rat and human hepatoma cells (Huc et al., 2012; Grasselli et al., 2013; Héliès-Toussaint et al., 2014; Peyre et al., 2014). However, investigations in human hepatoma cells were performed so far solely with the HepG2 cell line, which does not have a complete repertoire of xenobiotic metabolizing enzymes (XMEs), in particular regarding some cytochromes P450 (CYPs) and UDP-glucuronosyl transferases (UGTs) (Hewitt and Hewitt, 2004; Westerink and Schoonen, 2007a; Westerink and Schoonen, 2007b; Gerets et al., 2012). Moreover, the duration of BPA treatment in the experiments carried out in HepG2 was relatively short (i.e. 3 or 4 days) (Huc et al., 2012; Héliès-Toussaint et al., 2014; Peyre et al., 2014).

During the last decade, the human hepatoma HepaRG cell line has increasingly been used in the field of toxicology (Jossé et al., 2008; Dumont et al., 2010; Anthérieu et al., 2012; Andersson et al., 2012). Indeed, after differentiation, HepaRG cells express most of the XMEs present in the liver as well as key nuclear receptors regulating their expression including pregnane X receptor (PXR), aryl hydrocarbon receptor (AhR) and constitutive androstane receptor (CAR) (Aninat et al., 2006; Legendre et al., 2007; Anthérieu et al., 2012). The HepaRG cell line, which presents hepatic bipotent progenitor features, is able to enter into a differentiation program towards biliary-like and hepatocytelike cells (Gripon et al., 2002; Parent et al., 2004). The standard culture protocol allowing to obtain well-differentiated hepatocyte-like cells from the progenitor cells includes 2 weeks of proliferation followed by 2 weeks of differentiation, which is improved by the supplementation of the culture medium with 2\% dimethyl sulfoxide (DMSO) (Gripon et al., 2002; Cerec et al., 2007). 
Taking all these data into consideration, we determined whether long-term BPA treatment could induce lipid accumulation in HepaRG cells, using a protocol enabling to mimic a perinatal exposure. To this end, we first determined over the 4-week period of cell culture the kinetics of expression of proteins that are known to be differentially expressed during liver development. The kinetics of expression of eight enzymes involved in BPA metabolism was also assessed. In a second step, HepaRG cells were treated for 3 weeks with different concentrations of BPA ranging from 0.2 to $2000 \mathrm{nM}$, with the BPA treatment starting during the proliferating period. 


\section{MATERIALS AND METHODS}

\section{Chemicals}

BPA, DMSO and insulin were purchased from Sigma Aldrich (Saint-Quentin-Fallavier, France). William's E medium was obtained from Eurobio laboratories (Les Ulis, France). Fetal Bovine Serum (FBS) was purchased from Lonza (Levallois-Perret, France). Glutamine, penicillin and streptomycin were obtained from Thermo Fisher Scientific (Cergy Pontoise, France). Hydrocortisone hemisuccinate was purchased from Upjohn Pharmacia (Guancourt, France).

\section{Cell Culture and Treatments}

HepaRG cells were cultured according to the standard protocol described by Aninat et al. (2006) but with some adaptations related to the daily change of the culture medium. Briefly, HepaRG cells were seeded at a density of $2.610^{4}$ cells $/ \mathrm{cm}^{2}$ and were first incubated for one week in a William's E medium without phenol red and supplemented with 10\% FBS, 100 units/ml penicillin, $100 \mu \mathrm{g} / \mathrm{ml}$ streptomycin, $2 \mathrm{mM}$ glutamine, $5 \mu \mathrm{g} / \mathrm{ml}$ insulin and $50 \mu \mathrm{M}$ hydrocortisone hemisuccinate. After this first week, cells were exposed every day for 3 weeks with different concentrations of BPA $(0.2,2$, 20, 200 and $2000 \mathrm{nM}$ ). Hence, because of this daily treatment, the William's E medium was supplemented with 5\% FBS during this 3-week period. BPA was solubilized in DMSO, which was used at a final concentration of $0.01 \%$ for the first week of treatment (i.e. week 2 after seeding). Cells were thereafter cultured during the next two weeks of treatment (i.e. weeks 3 and 4 after seeding) in the presence of $1 \%$ DMSO in order to improve hepatocyte differentiation. In addition, experiments were carried out in untreated HepaRG cells cultured during a similar period of 4 weeks in order to determine the kinetics of expression of different genes of interest. For these experiments, the respective concentrations of FBS and DMSO added in the cultures were the same as those used for the BPA protocol treatment.

\section{Measurement of Neutral Lipids and Triglycerides}

The HCS LipidTOX ${ }^{\mathrm{TM}}$ green neutral lipid stain detection kit (Invitrogen, Eugene, Oregon, USA) was used in order to measure neutral lipids, according to the manufacturer's instructions. Briefly, control and treated cells were rinsed with phosphate buffered saline (PBS) and then fixed for 30 minutes in the dark with PBS containing 4\% paraformaldehyde and $2.5 \mu \mathrm{g} / \mathrm{ml}$ of the nuclear dye Hoechst 3342 , which was used to detect and count the HepaRG cells. Cells were rinsed three times with PBS and 
then incubated for 30 minutes in the dark with the LipidTOX ${ }^{\mathrm{TM}}$ stain. The PBS medium was then renewed and the 96-well plates were scanned with an Arrayscan VTI (Cellomics; Thermo Fisher Scientific, Villebon sur Yvette, France). At least 7500 cells were analyzed per well. Cellular triglycerides were measured with a colorimetric kit purchased from Biovision (Milpitas, CA), using the manufacturer's recommendations. The amount of cellular triglycerides was normalized to that of total proteins determined by the bicinchoninic acid (BCA) method.

\section{Isolation of RNA and Real-Time Quantitative PCR Analysis}

Total RNA was extracted from ca. $10^{6}$ HepaRG cells with the SV total RNA isolation system purchased from Promega (Charbonnières-les-Bains, France). This RNA isolation kit includes a DNase treatment step. RNA was reverse-transcribed into cDNA using the High-Capacity cDNA Archive kit purchased from Life technologies (Saint-Aubin, France). Real-time quantitative PCR (RT-qPCR) was then performed using the SYBR Green PCR Master Mix on an Applied Biosystems 7900HT Fast Real-Time PCR System (Applied Biosystem, Woolston, UK). Expression of the human TATA box binding protein (TBP) was used as reference, and the $2^{-\Delta \Delta C t}$ method was used to express the relative expression of each selected gene. Sequences of the primers used in this study are available on request.

\section{Statistical Analysis}

All results were expressed as mean \pm standard error of mean (SEM). Comparisons between the different conditions were performed with one-way analysis of variance (ANOVA). When ANOVA provided significant differences, individual means were compared with the post-hoc Dunnett's test. 


\section{RESULTS}

\section{Kinetics of Expression of Enzymes Differentially Expressed during Liver Development}

The main goal of this study was to set up a cellular model of perinatal BPA exposure by using the HepaRG cell line. To this end, we first determined over the 4-week period of cell culture after seeding the kinetics of expression of seven different proteins known to be differentially expressed during liver development: pyruvate kinase muscle isoform (PKM), aldolase A (ALDOA), albumin (ALB), aldolase B (ALDOB) as well as the cytochromes P450 3A7 (CYP3A7), CYP2E1 and CYP3A4. Indeed, the differential expression of these proteins has been extensively determined during liver development in rodents but also in humans (Imamura and Tanaka, 1972; Liao et al., 1980; Numazaki et al., 1984; Lacroix et al., 1997; Rich and Boobis, 1997; Lee et al., 2011). Notably, the expression of PKM2, ALDOA and CYP3A7 (Cyp3a16 in mouse) is specific to the fetal liver, whereas the expression of ALB, ALDOB, CYP2E1 and CYP3A4 (Cyp3a1/2 in rat and Cyp3a11 in mouse) increases during the perinatal period, or early after birth. In this study, the highest expression of PKM2, ALDOA and CYP3A7 was observed during the 2 weeks of proliferation, whereas the strongest expression of ALB, ALDOB, CYP2E1 and CYP3A4 was found during the differentiation stage (i.e. weeks 3 and 4 after seeding) (Fig. 1). Hence, by analogy with the in vivo situation reported in rodents and humans (Liao et al., 1980; Lacroix et al., 1997; Rich and Boobis, 1997; Hart et al., 2009), the period of cell culture around day 15 and day 18 after seeding could be considered as the "natal" period.

\section{Kinetics of Expression of Enzymes Involved in BPA Metabolism}

The expression of the main enzymes involved in BPA metabolism was also determined over the 4week period of cell culture after seeding. In human liver, BPA is mainly metabolized to BPAglucuronide by the UDP-glucuronosyltransferase 2B15 (UGT2B15) and to a lesser extent to BPAsulfate by the sulfotransferases 1A1 (SULT1A1) and 1A3/4 (SULT1A3/4) (Fig. 2) (Hanioka et al., 2008; Quesnot et al., 2014; Nahar et al., 2015; Thayer et al., 2015; Yalcin et al., 2016). Notably, BPAglucuronide and BPA-sulfate can be converted back to BPA by $\beta$-glucuronidase (GUSB) and steroid sulfatase (STS), respectively (Fig. 2) (Nahar et al., 2013; Nahar et al., 2015). A minor fraction of BPA can also by metabolized to catechol-BPA by several CYPs including CYP2C9, CYP2C18 and CYP2C19 (Fig. 2) (Niwa et al., 2001; Ye et al., 2011). In the present study, the expression of UGT2B15, STS, CYP2C9, CYP2C18 and CYP2C19 progressively increased during the 
differentiation process and reached a plateau around day 25 after seeding (Fig. 3). In contrast, the expression of SULT1A1 and GUSB was maximal between day 11 and day 13 and plateaued afterward (Fig. 3). Lastly, expression of SULT1A3/4 was maximal around day 13 and decreased later on (Fig. 3). Among these eight enzymes, GUSB, UGT2B15, CYP2C9 and CYP2C19 showed the highest expression in HepaRG cells (Fig. 4).

\section{Effects of BPA on Neutral Lipids, Triglycerides and Expression of Lipid-Responsive Genes}

HepaRG cells were treated daily with different concentrations of BPA (from 0.2 to $2000 \mathrm{nM}$ ) between day 7 and day 28 after seeding in order to determine whether chronic BPA exposure could induce steatosis in our cellular model. Our results showed that BPA significantly enhanced cellular neutral lipids and triglycerides at the $2 \mathrm{nM}$ concentration (Fig. 5). Interestingly, a non-monotonic dose response (NMDR) was observed for triglycerides and to a lesser extent for neutral lipids (Fig. 5). We also determined the mRNA levels of apolipoprotein A4 (APOA4), since we recently found that APOA4 expression was a sensitive marker of lipid accumulation in HepaRG cells incubated with fatty acids (Michaut et al., 2016). In the present study, APOA4 expression was also modulated by BPA in a non-monotonic manner with a significant increase observed at the $2 \mathrm{nM}$ concentration (Fig. 5). In contrast, BPA was not found to modify the expression of several proteins that coat lipid droplets, namely perilipin 1 (PLIN 1), perilipin 2 (PLIN2 also known as ADFP and ADRP) and perilipin 3 (also referred to as TIP47) (Fig. 5 and data not shown). These results were in keeping with our previous data showing that, compared with APOA4, expression of PLIN1 and PLIN 2 was significantly lower in fatty acid-loaded HepaRG cells (Michaut et al., 2016).

\section{Effects of BPA on the Expression of Genes Involved in Carbohydrate and Lipid Homeostasis}

In order to determine the mechanism whereby BPA could induce lipid accumulation in HepaRG cells, we further assessed the expression of different genes involved in carbohydrate and lipid homeostasis: ATP citrate lyase (ACLY), acetyl-CoA carboxylase alpha (ACACA), fatty acid synthase (FASN), thyroid hormone responsive protein (THRSP, also known as SPOT14), patatin-like phospholipase domain containing 3 (PNPLA3), 3-hydroxy-3-methylglutaryl-CoA reductase (HMGCR), peroxisome proliferator-activated receptor gamma (PPARG), solute carrier family 2 member 2 (SLC2A2, also known as GLUT2), pyruvate dehydrogenase kinase 4 (PDK4), carnitine palmitoyltransferase 1A (CPT1A), apolipoprotein B (APOB) and microsomal triglyceride transfer protein (MTTP). However, 
the expression of these different genes was not significantly modified by BPA treatment (data not shown).

\section{Effects of BPA on the Expression of Genes Involved in Oxidative Stress}

Because steatosis can be associated with oxidative stress (Begriche et al., 2013; Tariq et al., 2014), we also assessed the mRNA expression of the following genes: heme oxygenase 1 (HMOX1), $\mathrm{NAD}(\mathrm{P}) \mathrm{H}$ dehydrogenase quinone 1 (NQO1), nuclear factor of kappa light polypeptide gene enhancer in B-cells 1 (NFKB1), heat shock 70kDa protein 1A (HSPA1A, also known as HSP70-1A), glutathione S-transferase alpha 1/2 (GSTA1/2), GSTA3 and tribbles pseudokinase 3 (TRIB3). TRIB3 was investigated because its mRNA expression can be markedly enhanced in different conditions of stress, including when the cellular stores of the antioxidant glutathione are reduced (Ord and Ord, 2005; Aubert et al., 2012; Michaut et al., 2016). The expression of these genes was however unchanged (data not shown), thus indicating that BPA did not induce significant oxidative stress in our experimental conditions.

\section{Expression of ERR $\gamma$, PXR and their Targets Genes}

BPA is able to activate different nuclear receptors such as estrogen receptor (ER), estrogen related receptor $\gamma(\mathrm{ERR} \gamma)$, glucocorticoid receptor (GR), AhR and PXR but BPA binding affinity varies greatly from one receptor to another (Takayanagi et al., 2006; Krüger et al., 2008; Vandenberg et al., 2009; Riu et al., 2011; Rubin, 2011; Sui et al., 2012; Peyre et al., 2014; Rezg et al., 2014). Notably, BPA strongly binds to human ERR $\gamma$ with a binding affinity constant $\left(\mathrm{K}_{\mathrm{d}}\right)$ of ca. $5 \mathrm{nM}$, while its affinity for ER $\alpha$ and ER $\beta$ was reported to be 80- and 100-fold lower, respectively (Takayanagi et al., 2006; Okada et al., 2008). Hence, it has been postulated that ERR $\gamma$ activation could significantly mediate some toxic effects induced by BPA in different experimental models (Héliès-Toussaint et al., 2014; Tohmé et al., 2014; Song et al., 2015). Importantly, ERR $\gamma$ is able to regulate different key metabolic processes such as gluconeogenesis, fatty acid oxidation and oxidative phosphorylation (Alaynick et al., 2007; Eichner et al., 2010; Kim et al., 2012). Taking these data into consideration, we assessed the effects of BPA on the expression of three ERR $\gamma$ target genes, namely phosphoenolpyruvate carboxykinase 1 (PCK1), succinate dehydrogenase complex subunit D (SDHD) and estrogen-related receptor alpha (ESRRA) (Alaynick et al., 2007; Eichner et al., 2010; Kim et al., 2012). However, the expression of these genes was unchanged in treated HepaRG cells, whatever the BPA concentration (Fig. 6A). In addition, BPA did not alter the expression of PDK4 (data not shown), another target 
gene of ERR $\gamma$ (Lee et al., 2012; Poidatz et al., 2012). Altogether, these data suggested that BPA did not activate ERR $\gamma$ in HepaRG cells in our experimental conditions, despite additional investigations showing that the mRNA levels of ERR $\gamma(E S R R G)$ increased sharply during HepaRG proliferation/differentiation, to rapidly reach a plateau around day 13 after seeding (Fig. 6A).

BPA is also an effective agonist of human PXR (Sui et al., 2012; Kuzbari et al., 2013), as many other xenobiotics (Zhang et al., 2008; Tolson and Wang, 2010). Notably, PXR regulates not only the expression of numerous XMEs such as CYPs, UGTs and SULTs (Zhang et al., 2008; Tolson and Wang, 2010), but also that of enzymes and other proteins involved in carbohydrate and lipid homeostasis (Moreau et al., 2008; Wada et al., 2009; Gao and Xie, 2012; Koutsounas et al., 2013; Li et al., 2015). Accordingly, we assessed the effects of BPA on the expression of different PXR target genes, namely CYP3A4, CYP2C9 and the CD36 molecule (CD36, also known as FAT) (Zhang et al., 2008; Tolson and Wang, 2010). However, the mRNA levels of these genes were not modified in HepaRG cells treated with the different concentrations of BPA (Fig. 6B). Contrasting with ESRRG expression, the mRNA levels of PXR (NR112) increased progressively during the proliferation and differentiation stages of HepaRG, and plateaued around day 25 after seeding (Fig. 6B).

\section{Effects of BPA on the Expression of Genes Involved in its Own Biotransformation}

Numerous studies carried out in different in vitro and in vivo models have reported that BPA is able to modulate the expression and/or the activity of numerous XMEs including CYPs, UGTs and SULTs (Hanioka et al., 2000; Nahar et al., 2014; Quesnot et al., 2014). Hence, in a last series of investigations we wished to determine whether BPA altered in HepaRG cells the expression of the main enzymes involved in its own biotransformation, namely UGT2B15, GUSB, SULT1A1, SULT1A3/4, STS, CYP2C9, CYP2C18 and CYP2C19 (Fig. 2). However, the expression of these enzymes was unchanged in treated HepaRG cells, whatever the BPA concentration (data not shown). It is noteworthy that in addition to CYP2C9 (see above), other BPA metabolizing enzymes such as CYP2C19 and SULT1A1 are also PXR targets (Tolson and Wang, 2010). Thus, the lack of BPA effects on CYP2C19 and SULT1A1 expression was fully consistent with our finding that PXR was not activated in treated HepaRG cells. 


\section{DISCUSSION}

There is an increasing concern regarding the potential harmful effects of human BPA exposure on carbohydrate and lipid homeostasis. Indeed, BPA is greatly suspected to favor obesity, insulin resistance, type 2 diabetes and liver steatosis (Trasande et al., 2012; Khalil et al., 2014; Oppeneer and Robien, 2015; Rancière et al., 2015). Regarding BPA-induced steatosis, different hypotheses can be put forward including the indirect metabolic effects of obesity and insulin resistance (Marmugi et al., 2012; Polyzos et al., 2012), or direct effects of BPA on lipid homeostasis in hepatocytes (Huc et al., 2012; Grasselli et al., 2013; Peyre et al., 2014; Héliès-Toussaint et al., 2014). However, despite a wealth of experimental studies, the mechanisms whereby BPA is able to alter carbohydrate and lipid homeostasis are still poorly understood. Notably, BPA-induced adverse effects could be more important when BPA exposure occurs during the perinatal period, or in the early postnatal years (Calkins and Devaskar, 2011; Rochester, 2013).

Taking all these elements into consideration, a first aim of the present study was to determine whether BPA could induce steatosis in HepaRG cells using a model of perinatal exposure. To this end, we first assessed the expression of several genes known to be differentially expressed during liver development such as PKM, ALDOA, ALDOB, ALB, and three different CYPs (Liao et al., 1980; Lacroix et al., 1997; Rich and Boobis, 1997; Hart et al., 2009). According to the different profiles of gene expression, our results indicated that the period of HepaRG cell culture around day 15 and day 18 after seeding could be considered as the "natal" period (Fig. 1). Consequently, HepaRG cells were treated daily with different concentrations of BPA (ranging from 0.2 to $2000 \mathrm{nM}$ ) between day 7 and day 28 after seeding, in order to determine whether chronic BPA exposure could induce steatosis in our cell model. We found that BPA increased neutral lipids and triglycerides in treated cells in a NMDR manner, although these effects were statistically significant only for the $2 \mathrm{nM}$ concentration (Fig. 5). Notably, this concentration is within the range of concentrations found in human serum in the context of environmental exposure (Alonso-Magdalena et al., 2010a; Vandenberg et al., 2010). The NMDR profile observed for neutral lipids and triglycerides was also observed for APOA4 expression (Fig. 5). Interestingly, a recent review of the literature reported that NMDR curves are rather common with BPA (Vandenberg, 2014). It has been proposed that a NMDR profile can occur whenever two or more opposite monotonic dose response curves overlap (Vandenberg et al., 2009; Vandenberg, 2014). Thus, depending of the concentrations, BPA might have contrary effects on triglyceride synthesis on the one hand and on triglyceride disposal on the other hand. 
Despite our attempt to decipher how BPA induced steatosis in HepaRG cells, none of our results gave us a starting hypothesis. Importantly, abnormal accumulation of triglycerides within hepatocytes can result from an unbalance between different metabolic fluxes including the entry of fatty acids via specific transporters (e.g. CD36), their esterification into triglycerides, their degradation by the peroxisomal and mitochondrial $\beta$-oxidation pathways and their output from the cells after VLDL assembly (Cohen et al., 2011; Begriche et al., 2013). In this study, the expression of several key factors involved in these metabolic processes was however found unchanged. In addition, we found no modification in the expression of different known targets of ERR $\gamma$ and PXR, thus suggesting that these nuclear receptors are not involved in BPA-induced steatosis, either directly or indirectly. A microarray analysis could be helpful in order to determine whether the dysregulation of other genes might play a role in fat accumulation. It would be also interesting to study the metabolic fluxes linked to lipogenesis, $\beta$-oxidation and VLDL output and the activity of key enzymes involved in these metabolic pathways.

As previously mentioned, the human hepatoma HepaRG cell line has increasingly been used in order to study drug metabolism and toxicity. Indeed, this cell line expresses most of the XMEs present in the liver as well as different key nuclear receptors regulating their expression (Aninat et al., 2006; Legendre et al., 2007; Jossé et al., 2008; Dumont et al., 2010; Andersson et al., 2012; Anthérieu et al., 2012). In this study, we found that HepaRG cells expressed relatively high levels of different enzymes involved in BPA biotransformation (Fig. 2), in particular GUSB, UGT2B15, CYP2C9 and CYP2C19 (Fig. 4). Interestingly, the kinetics of expression of UGT2B15, CYP2C9 and CYP2C19 over a 32-day period of cell culture after seeding (Fig. 3) was almost similar to that of ALDOB (Fig. 1), with a progressive expression between day 6 and day 25 subsequently followed by a plateau. These data suggest that the developmental expression of these XME genes could be regulated by factors similar to those involved in ALDOB expression such as the liver-enriched transcription factor hepatocyte nuclear factor $1 \alpha(\mathrm{HNF}-1 \alpha)$ (Tsutsumi et al., 1989; Ito et al., 1995). Our data regarding UGT2B15 and GUSB (Fig. 3) also suggest that their developmental expression could be very different, which might have important consequences on BPA biotransformation. For instance, the combination of relatively high expression of GUSB and low expression of UGT2B15 during early development could favor BPA accumulation and the occurrence of deleterious effects.

Taking all these data into consideration, the HepaRG cell line could be a valuable tool in order to gain further information regarding BPA biotransformation in human hepatocytes, in particular during the developmental period. Our results also underline the relevance of the HepaRG model in order to 
investigate the hepatic effects of endocrine disruptors that are expected to occur during the perinatal period. However, it should be kept in mind that the HepaRG cell line is derived from a female patient (Gripon et al., 2002). This feature might be important because previous investigations carried out in rodents reported that perinatal exposure of BPA could induce differential effects on lipid and carbohydrate homeostasis between male and female offspring (Miyawaki et al., 2007; Somm et al., 2009; Alonso-Magdalena et al., 2010b). Moreover, it is well-known that the expression and activity of different XMEs can significantly vary depending on the sex (Mugford and Kedderis, 1998; Waxman and Holloway, 2009). Thus, one cannot exclude the possibility that our results might not have been similar with cells from a male donor. 


\section{ACKNOWLEDGMENT}

This work was mostly supported by a grant from the Agence Nationale de la Recherche (ANR contract PERINATOX 2010 CESA 005 03). Part of the work was also supported by INSERM (Institut National de la Recherche et de la Santé Médicale). We are grateful to Remy Le Guével from the ImPACcell platform (Biosit, Rennes) for his excellent technical support. 


\section{REFERENCES}

Alaynick WA, Kondo RP, Xie W, He W, Dufour CR, Downes M, Jonker JW, Giles W, Naviaux RK, Giguère V, Evans RM. 2007. ERR $\gamma$ directs and maintains the transition to oxidative metabolism in the postnatal heart. Cell Metab 6:13-24.

Alonso-Magdalena P, Ropero AB, Soriano S, Quesada I, Nadal A. 2010a. Bisphenol-A: a new diabetogenic factor? Hormones 9:118-126.

Alonso-Magdalena P, Vieira E, Soriano S, Menes L, Burks D, Quesada I, Nadal A. 2010b. Bisphenol A exposure during pregnancy disrupts glucose homeostasis in mothers and adult male offspring. Environ Health Perspect 118:1243-1250.

Andersson TB, Kanebratt KP, Kenna JG. 2012. The HepaRG cell line: a unique in vitro tool for understanding drug metabolism and toxicology in human. Expert Opin Drug Metab Toxicol 8:909920.

Aninat C, Piton A, Glaise D, Le Charpentier T, Langouët S, Morel F, Guguen-Guillouzo C, Guillouzo A. 2006. Expression of cytochromes P450, conjugating enzymes and nuclear receptors in human hepatoma HepaRG cells. Drug Metab Dispos 34:75-83.

Anthérieu S, Chesné C, Li R, Guguen-Guillouzo C, Guillouzo A. 2012. Optimization of the HepaRG cell model for drug metabolism and toxicity studies. Toxicol In Vitro 26:1278-1285.

Aubert J, Begriche K, Delannoy M, Morel I, Pajaud J, Ribault C, Lepage S, McGill MR, Lucas-Clerc C, Turlin B, Robin MA, Jaeschke H, Fromenty B. 2012. Differences in early acetaminophen hepatotoxicity between obese ob/ob and db/db mice. J Pharmacol Exp Ther 342:676-687.

Begriche K, Massart J, Robin MA, Bonnet F, Fromenty B. 2013. Mitochondrial adaptations and dysfunctions in nonalcoholic fatty liver disease. Hepatology 58:1497-1507.

Calkins K, Devaskar SU. 2011. Fetal origins of adult disease. Curr Prob Pediatr AdolescHealth Care 41:158-176. 
Cerec V, Glaise D, Garnier D, Morosan S, Turlin B, Drenou B, Gripon P, Kremsdorf D, GuguenGuillouzo C, Corlu A. 2007. Transdifferentiation of hepatocyte-like cells from the human hepatoma HepaRG cell line through bipotent progenitor. Hepatology 45:957-967.

Cohen JC, Horton JD, Hobbs HH. 2011. Human fatty liver disease: old questions and new insights. Science 332:1519-1523.

Dumont J, Jossé R, Lambert C, Anthérieu S, Laurent V, Loyer P, Robin MA, Guillouzo A. 2010. Preferential induction of the AhR gene battery in HepaRG cells after a single or repeated exposure to heterocyclic aromatic amines. Toxicol Appl Pharmacol 249:91-100.

Eichner LJ, Perry MC, Dufour CR, Bertos N, Park M, St-Pierre J, Giguère V. 2010. miR-378*

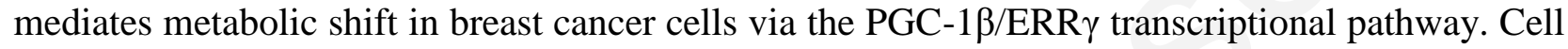
Metab 12:352-361.

Gao J, Xie W. 2012. Targeting xenobiotic receptors PXR and CAR for metabolic diseases. Trends Pharmacol Sci 33:552-558.

Gerets HH, Tilmant K, Gerin B, Chanteux H, Depelchin BO, Dhalluin S, Atienzar FA. 2012. Characterization of primary human hepatocytes, HepG2 cells, and HepaRG cells at the mRNA level and CYP activity in response to inducers and their predictivity for the detection of human hepatotoxins. Cell Biol Toxicol 28:69-87.

Grasselli E, Cortese K, Voci A, Vergani L, Fabbri R, Barmo C, Gallo G, Canesi L. 2013. Direct effects of Bisphenol A on lipid homeostasis in rat hepatoma cells. Chemosphere 91:1123-1129.

Gripon P, Rumin S, Urban S, Le Seyec J, Glaise D, Cannie I, Guyomard C, Lucas J, Trepo C, GuguenGuillouzo C. 2002. Infection of a human hepatoma cell line by hepatitis B virus. Proc Natl Acad Sci USA 99:15655-15660.

Hanioka N, Jinno H, Tanaka-Kagawa T, Nishimura T, Ando M. 2000. Interaction of bisphenol A with rat hepatic cytochrome P450 enzymes. Chemosphere 41:973-978.

Hanioka N, Naito T, Narimatsu S. 2008. Human UDP-glucuronosyltransferase isoforms involved in bisphenol A glucuronidation. Chemosphere 74:33-36. 
Hart SN, Cui Y, Klaassen CD, Zhong XB. 2009. Three patterns of cytochrome P450 gene expression during liver maturation in mice. Drug Metab Dispos 37:116-121.

Héliès-Toussaint C, Peyre L, Costanzo C, Chagnon MC, Rahmani R. 2014. Is bisphenol S a safe substitute for bisphenol A in terms of metabolic function? An in vitro study. Toxicol Appl Pharmacol 280:224-235.

Hewitt NJ, Hewitt P. 2004. Phase I and II enzyme characterization of two sources of HepG2 cell lines. Xenobiotica 34:243-256.

Huc L, Lemarié A, Guéraud F, Héliès-Toussaint C. 2012. Low concentrations of bisphenol A induce lipid accumulation mediated by the production of reactive oxygen species in the mitochondria of HepG2 cells. Toxicol In Vitro 26:709-717.

Imamura K, Tanaka T. 1972. Multimolecular forms of pyruvate kinase from rat and other mammalian tissues. I. Electrophoretic studies. J Biochem 71:1043-1051.

Ito K, Tsutsumi R, Ishikawa K, Tsutsumi K. 1995. Developmental alteration of the chromatin state at promoter/replication origin region of the aldolase B locus precedes transcriptional activation in the liver. Dev Genet 17:312-318.

Jossé R, Aninat C, Glaise D, Dumont J, Fessard V, Morel F, Poul JM, Guguen-Guillouzo C, Guillouzo A. 2008. Long-term functional stability of human HepaRG hepatocytes and use for chronic toxicity and genotoxicity studies. Drug Metab Dispos 36:1111-1118.

Khalil N, Ebert JR, Wang L, Belcher S, Lee M, Czerwinski SA, Kannan K. 2014. Bisphenol A and cardiometabolic risk factors in obese children. Sci Total Environ 470-471:726-732.

Kim DK, Ryu D, Koh M, Lee MW, Lim D, Kim MJ, Kim YH, Cho WJ, Lee CH, Park SB, Koo SH, Choi HS. 2012. Orphan nuclear receptor estrogen-related receptor $\gamma(E R R \gamma)$ is key regulator of hepatic gluconeogenesis. J Biol Chem 287:21628-21639.

Koutsounas I, Theocharis S, Patsouris E, Giaginis C. 2013. Pregnane X receptor (PXR) at the crossroads of human metabolism and disease. Curr Drug Metab 14:341-350. 
Krüger T, Long M, Bonefeld-Jørgensen EC. 2008. Plastic components affect the activation of the aryl hydrocarbon and the androgen receptor. Toxicology 246:112-123.

Kuzbari O, Peterson CM, Franklin MR, Hathaway LB, Johnstone EB, Hammoud AO, Lamb JG. 2013. Comparative analysis of human CYP3A4 and rat CYP3A1 induction and relevant gene expression by bisphenol A and diethylstilbestrol: implications for toxicity testing paradigms. Reprod Toxicol 37:24-30.

Lacroix D, Sonnier M, Moncion A, Cheron G, Cresteil T. 1997. Expression of CYP3A in the human liver. Evidence that the shift between CYP3A7 and CYP3A4 occurs immediately after birth. Eur J Biochem 247:625-634.

Lee JS, Ward WO, Liu J, Ren H, Vallanat B, Delker D, Corton JC. 2011. Hepatic xenobiotic metabolizing enzyme and transporter gene expression through the life stages of the mouse. PLoS One 6:e24381.

Lee JH, Kim EJ, Kim DK, Lee JM, Park SB, Lee IK, Harris RA, Lee MO, Choi HS. 2012. Hypoxia induces PDK4 gene expression through induction of the orphan nuclear receptor ERR $\gamma$. PLoS One 7:e46324.

Legendre C, Hori T, Loyer P, Aninat C, Ishida S, Glaise D, Lucas-Clerc C, Boudjema K, GuguenGuillouzo C, Corlu A, Morel F. 2009. Drug-metabolising enzymes are down-regulated by hypoxia in differentiated human hepatoma HepaRG cells: HIF-1a involvement in CYP3A4 repression. Eur J Cancer 45:2882-2892.

Li L, Li H, Garzel B, Yang H, Sueyoshi T, Li Q, Shu Y, Zhang J, Hu B, Heyward S, Moeller T, Xie W, Negishi M, Wang H. 2015. SLC13A5 is a novel transcriptional target of the pregnane X receptor and sensitizes drug-induced steatosis in human liver. Mol Pharmacol 87:674-682.

Liao WS, Conn AR, Taylor JM. 1980. Changes in rat $\alpha 1$-fetoprotein and albumin mRNA levels during fetal and neonatal development. J Biol Chem 255:10036-10039.

Marmugi A, Ducheix S, Lasserre F, Polizzi A, Paris A, Priymenko N, Bertrand-Michel J, Pineau T, Guillou H, Martin PG, Mselli-Lakhal L. 2012. Low doses of bisphenol A induce gene expression 
related to lipid synthesis and trigger triglyceride accumulation in adult mouse liver. Hepatology 55: 395-407.

Michaut A, Le Guillou D, Moreau C, Bucher S, McGill MR, Martinais S, Gicquel T, Robin MA, Jaeschke H, Fromenty B. 2016. A cellular model to study drug-induced liver injury in nonalcoholic fatty liver disease: application to acetaminophen. Toxicol Appl Pharmacol 292:40-55.

Miyawaki J, Sakayama K, Kato H, Yamamoto H, Masuno H. 2007. Perinatal and postnatal exposure to bisphenol a increases adipose tissue mass and serum cholesterol level in mice. $\mathrm{J}$ Atheroscler Thromb 14:245-252.

Moreau A, Vilarem MJ, Maurel P, Pascussi JM. 2008. Xenoreceptors CAR and PXR activation and consequences on lipid metabolism, glucose homeostasis, and inflammatory response. Mol Pharm 5:35-41.

Mugford CA, Kedderis GL. 1998. Sex-dependent metabolism of xenobiotics. Drug Metab Rev 30:441-498.

Nahar MS, Liao C, Kannan K, Dolinoy DC. 2013. Fetal liver bisphenol A concentrations and biotransformation gene expression reveal variable exposure and altered capacity for metabolism in humans. J Biochem Mol Toxicol 27:116-123.

Nahar MS, Kim JH, Sartor MA, Dolinoy DC. 2014. Bisphenol A-associated alterations in the expression and epigenetic regulation of genes encoding xenobiotic metabolizing enzymes in human fetal liver. Environ Mol Mutagen 55:184-195.

Nahar MS, Liao C, Kannan K, Harris C, Dolinoy DC. 2015. In utero bisphenol A concentration, metabolism, and global DNA methylation across matched placenta, kidney, and liver in the human fetus. Chemosphere 124:54-60.

Niwa T, Fujimoto M, Kishimoto K, Yabusaki Y, Ishibashi F, Katagiri M. 2001. Metabolism and interaction of bisphenol A in human hepatic cytochrome P450 and steroidogenic CYP17. Biol Pharm Bull 24:1064-1067.

Numazaki M, Tsutsumi K, Tsutsumi R, Ishikawa K. 1984. Expression of aldolase isozyme mRNAs in fetal rat liver. Eur J Biochem 142:165-170. 
Okada H, Tokunaga T, Liu X, Takayanagi S, Matsushima A, Shimohigashi Y. 2008. Direct evidence revealing structural elements essential for the high binding ability of bisphenol A to human estrogenrelated receptor- $\gamma$. Environ Health Perspect 116:32-38.

Oppeneer SJ, Robien K. 2015. Bisphenol A exposure and associations with obesity among adults: a critical review. Public Health Nutr 18:1847-1863.

Ord D, Ord T. 2005. Characterization of human NIPK (TRB3, SKIP3) gene activation in stressful conditions. Biochem Biophys Res Commun 330:210-218.

Parent R, Marion MJ, Furio L, Trépo C, Petit MA. 2004. Origin and characterization of a human bipotent liver progenitor cell line. Gastroenterology 126:1147-1156.

Peyre L, Rouimi P, de Sousa G, Héliès-Toussaint C, Carré B, Barcellini S, Chagnon MC, Rahmani R. 2014. Comparative study of bisphenol A and its analogue bisphenol S on human hepatic cells: a focus on their potential involvement in nonalcoholic fatty liver disease. Food Chem Toxicol 70:918.

Poidatz D, Dos Santos E, Brulé A, De Mazancourt P, Dieudonné MN. 2012. Estrogen-related receptor gamma modulates energy metabolism target genes in human trophoblast. Placenta 33:688-695.

Polyzos SA, Kountouras J, Deretzi G, Zavos C, Mantzoros CS. 2012. The emerging role of endocrine disruptors in pathogenesis of insulin resistance: a concept implicating nonalcoholic fatty liver disease. Curr Mol Med 12:68-82.

Quesnot N, Bucher S, Fromenty B, Robin MA. 2014. Modulation of metabolizing enzymes by bisphenol A in human and animal models. Chem Res Toxicol 27:1463-1473.

Rancière F, Lyons JG, Loh VH, Botton J, Galloway T, Wang T, Shaw JE, Magliano DJ. 2015. Bisphenol A and the risk of cardiometabolic disorders: a systematic review with meta-analysis of the epidemiological evidence. Environ Health 14:46.

Rezg R, El-Fazaa S, Gharbi N, Mornagui B. 2014. Bisphenol A and human chronic diseases: current evidences, possible mechanisms, and future perspectives. Environ Int 64:83-90. 
Rich KJ, Boobis AR. 1997. Expression and inducibility of P450 enzymes during liver ontogeny. Microsc Res Tech 39:424-435.

Riu A, le Maire A, Grimaldi M, Audebert M, Hillenweck A, Bourguet W, Balaguer P, Zalko D. 2011. Characterization of novel ligands of $\operatorname{ER} \alpha, \operatorname{Er} \beta$, and PPAR $\gamma$ : the case of halogenated bisphenol A and their conjugated metabolites. Toxicol Sci 122:372-382.

Rochester JR. 2013. Bisphenol A and human health: a review of the literature. Reprod Toxicol 42:132-155.

Somm E, Schwitzgebel VM, Toulotte A, Cederroth CR, Combescure C, Nef S, Aubert ML, Hüppi PS. 2009. Perinatal exposure to bisphenol a alters early adipogenesis in the rat. Environ Health Perspect 117:1549-1555.

Rubin BS. 2011. Bisphenol A: an endocrine disruptor with widespread exposure and multiple effects. J Steroid Biochem Mol Biol 127:27-34.

Song H, Zhang T, Yang P, Li M, Yang Y, Wang Y, Du J, Pan K, Zhang K. 2015. Low doses of bisphenol A stimulate the proliferation of breast cancer cells via ERK1/2/ERR $\gamma$ signals. Toxicol In Vitro 30:521-528.

Sui Y, Ai N, Park SH, Rios-Pilier J, Perkins JT, Welsh WJ, Zhou C. 2012. Bisphenol A and its analogues activate human pregnane X receptor. Environ Health Perspect 120:399-405.

Takayanagi S, Tokunaga T, Liu X, Okada H, Matsushima A, Shimohigashi Y. 2006. Endocrine disruptor bisphenol A strongly binds to human estrogen-related receptor $\gamma$ (ERR $\gamma$ ) with high constitutive activity. Toxicol Lett 167:95-105.

Tariq Z, Green CJ, Hodson L. 2014. Are oxidative stress mechanisms the common denominator in the progression from hepatic steatosis towards non-alcoholic steatohepatitis (NASH)? Liver Int 34:e180-e190.

Thayer KA, Doerge DR, Hunt D, Schurman SH, Twaddle NC, Churchwell MI, Garantziotis S, Kissling GE, Easterling MR, Bucher JR, Birnbaum LS. 2015. Pharmacokinetics of bisphenol A in humans following a single oral administration. Environ Int 83:107-115. 
Tohmé M, Prud'homme SM, Boulahtouf A, Samarut E, Brunet F, Bernard L, Bourguet W, Gibert Y, Balaguer P, Laudet V. 2014. Estrogen-related receptor $\gamma$ is an in vivo receptor of bisphenol A. FASEB J 28:3124-3133.

Tolson AH, Wang H. 2010. Regulation of drug-metabolizing enzymes by xenobiotic receptors: PXR and CAR. Adv Drug Deliv Rev 62:1238-1249.

Trasande L, Attina TM, Blustein J. 2012. Association between urinary bisphenol A concentration and obesity prevalence in children and adolescents. JAMA 308:1113-1121.

Tsutsumi K, Ito K, Ishikawa K. 1989. Developmental appearance of transcription factors that regulate liver-specific expression of the aldolase B gene. Mol Cell Biol 9:4923-4931.

Vandenberg LN, Maffini MV, Sonnenschein C, Rubin BS, Soto AM. 2009. Bisphenol-A and the great divide: a review of controversies in the field of endocrine disruption. Endocr Rev 30:75-95.

Vandenberg LN, Chahoud I, Heindel JJ, Padmanabhan V, Paumgartten FJ, Schoenfelder G. 2010. Urinary, circulating, and tissue biomonitoring studies indicate widespread exposure to bisphenol A. Environ Health Perspect 118:1055-1070.

Vandenberg LN. 2014. Non-monotonic dose responses in studies of endocrine disrupting chemicals: bisphenol a as a case study. Dose Response 12:259-276.

Wada T, Gao J, Xie W. 2009. PXR and CAR in energy metabolism. Trends Endocrinol Metab 20:273279.

Waxman DJ, Holloway MG. 2009. Sex differences in the expression of hepatic drug metabolizing enzymes. Mol Pharmacol 76: 215-228.

Wei J, Sun X, Chen Y, Li Y, Song L, Zhou Z, Xu B, Lin Y, Xu S. 2014. Perinatal exposure to bisphenol A exacerbates nonalcoholic steatohepatitis-like phenotype in male rat offspring fed on a high-fat diet. J Endocrinol 222:313-325.

Westerink WM, Schoonen WG. 2007a. Cytochrome P450 enzyme levels in HepG2 cells and cryopreserved primary human hepatocytes and their induction in HepG2 cells. Toxicol In Vitro 21:1581-1591. 
Westerink WM, Schoonen WG. 2007b. Phase II enzyme levels in HepG2 cells and cryopreserved primary human hepatocytes and their induction in HepG2 cells. Toxicol In Vitro 21:1592-1602.

Xu CX, Wang C, Zhang ZM, Jaeger CD, Krager SL, Bottum KM, Liu J, Liao DF, Tischkau SA. 2015. Aryl hydrocarbon receptor deficiency protects mice from diet-induced adiposity and metabolic disorders through increased energy expenditure. Int J Obes 39:1300-1309.

Yalcin EB, Kulkarni SR, Slitt AL, King R. 2016. Bisphenol a sulfonation is impaired in metabolic and liver disease. Toxicol Appl Pharmacol 292:75-84.

Ye X, Zhou X, Needham LL, Calafat AM. 2011. In-vitro oxidation of bisphenol A: Is bisphenol A catechol a suitable biomarker for human exposure to bisphenol A? Anal Bioanal Chem 399:10711079.

Zhang B, Xie W, Krasowski MD. 2008. PXR: a xenobiotic receptor of diverse function implicated in pharmacogenetics. Pharmacogenomics 9:1695-1709. 

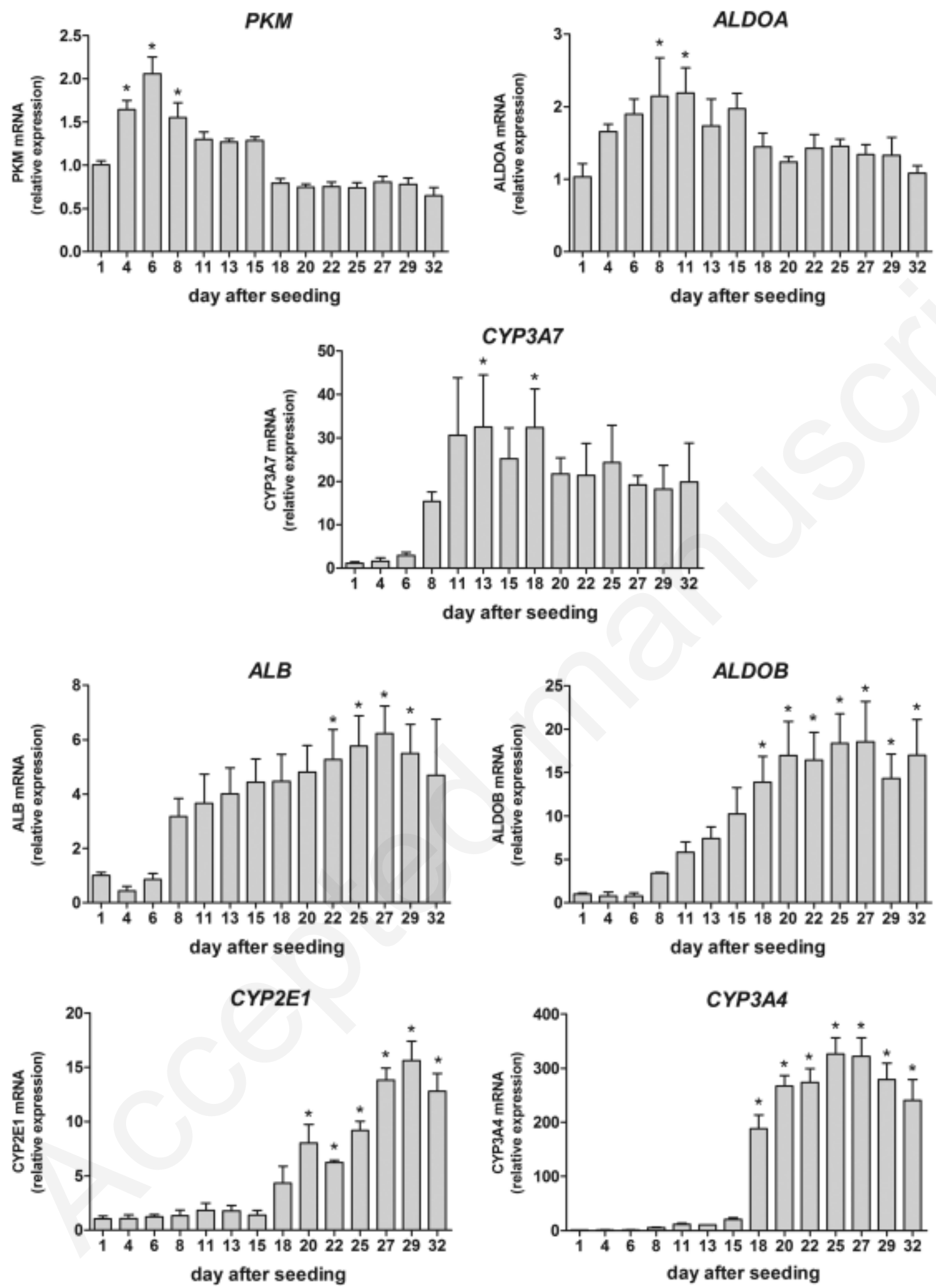

Figure 1. Kinetics of expression in HepaRG cells of seven different proteins known to be differentially expressed during liver development. The mRNA levels of each protein were determined 
over a 32-day period of cell culture after seeding. Expression of TBP was used as reference. Results are means \pm SEM for 3 independent cultures. ${ }^{*}$ Significantly different from HepaRG cells at day 1 after seeding $(\mathrm{P}<0.05)$.

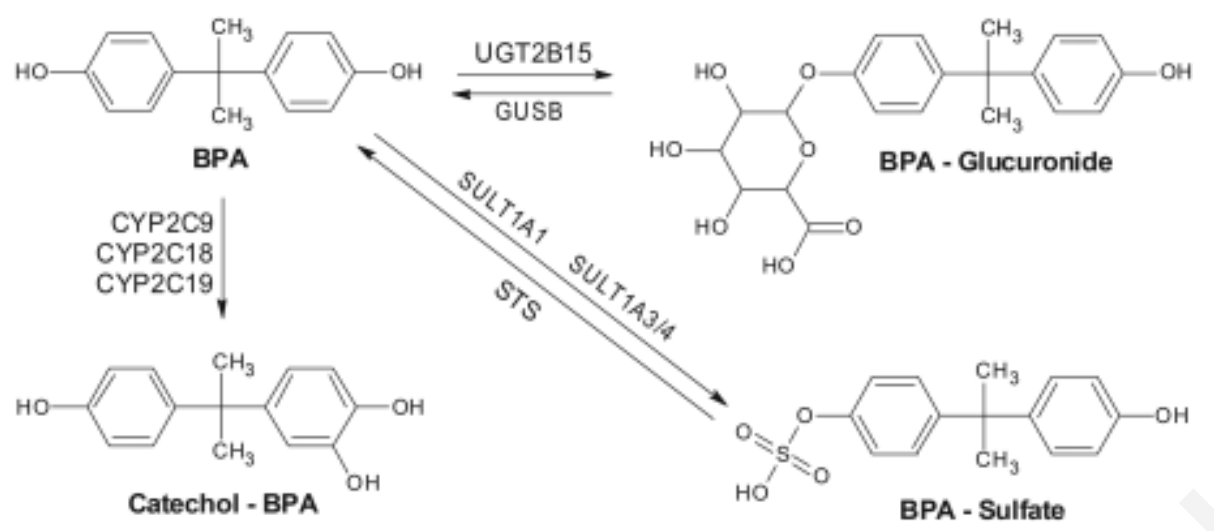

Figure 2. Schematic representation of BPA metabolism in human according to the current literature. The correspondence of the different abbreviations and further information is given in the text. 

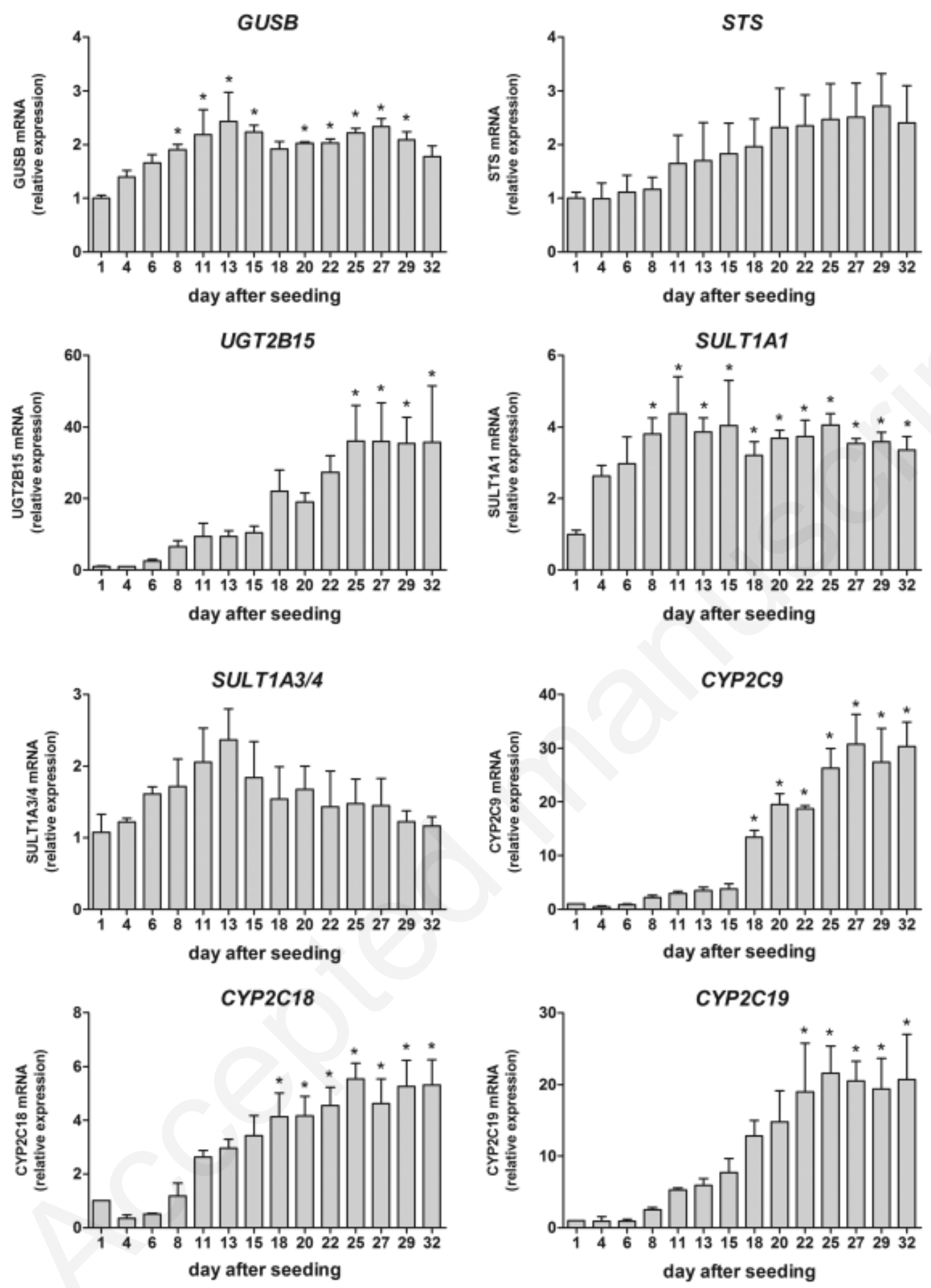

Figure 3. Kinetics of expression in HepaRG cells of eight different enzymes involved in BPA metabolism in human according to the current literature. The mRNA levels of each protein were determined over a 32-day period of cell culture after seeding. Expression of TBP was used as 
reference. Results are means \pm SEM for 3 independent cultures. *Significantly different from HepaRG cells at day 1 after seeding $(\mathrm{P}<0.05)$.

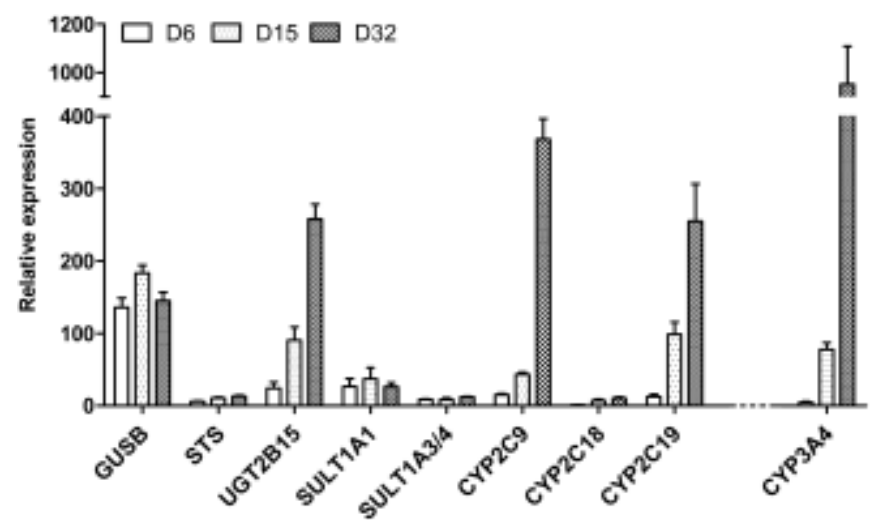

Figure 4. Comparative mRNA expression in HepaRG cells of eight different enzymes involved in BPA metabolism. The relative expression are shown for day 6 (D6), day 15 (D15) and day 32 (D32) after seeding. The relative expression of CYP2C18 at D6 was arbitrary set to 1. For proper comparison, the figure also shows the expression of CYP3A4, a prototypical XME that is highly expressed in human liver. 
A.
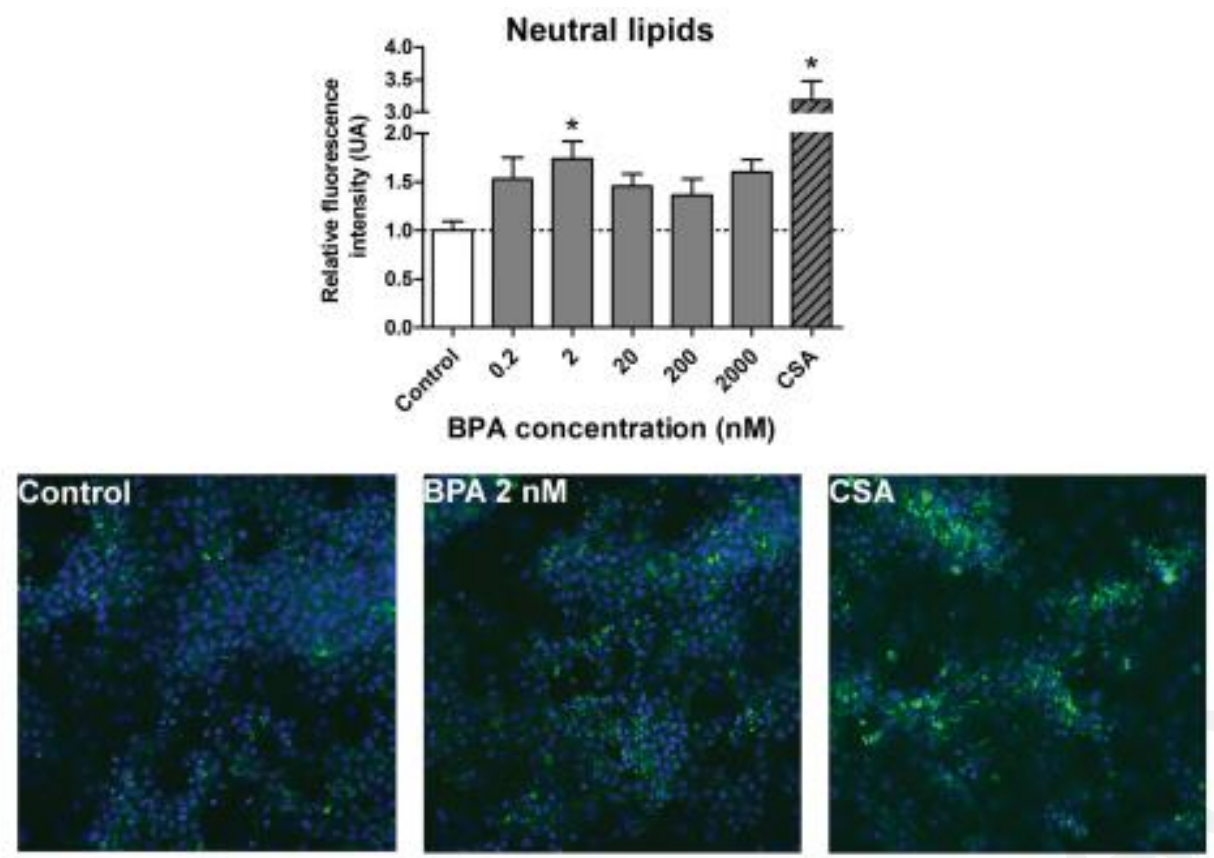

B.
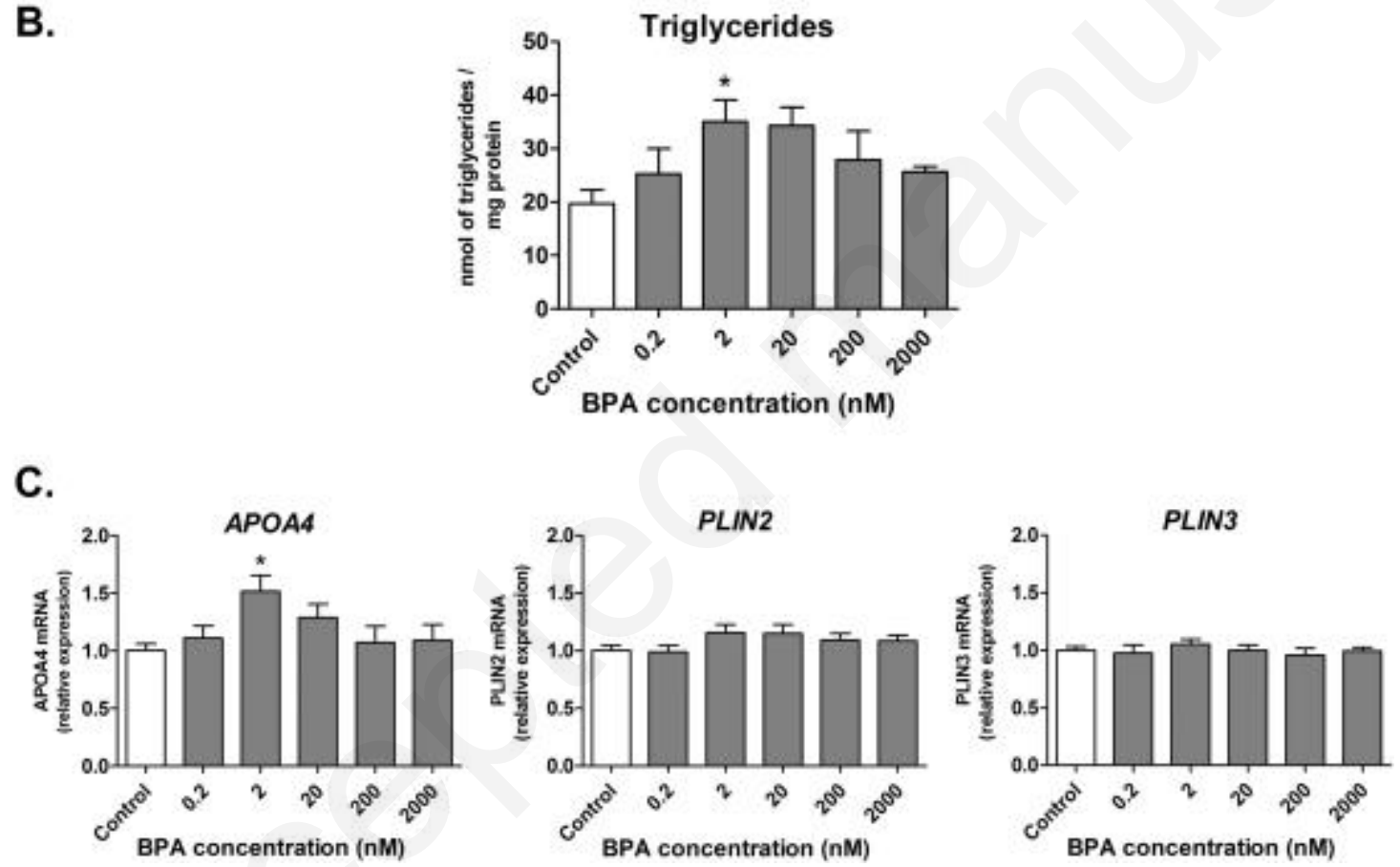

Figure 5. BPA-induced steatosis in HepaRG cells. Cells were treated with different concentrations of BPA (from 0.2 to $2000 \mathrm{nM}$ ) during 3 consecutive weeks and different parameters linked to steatosis were subsequently assessed. A. Determination of neutral lipids with the LipidTOX ${ }^{\mathrm{TM}}$ stain. Results are means \pm SEM for 3 independent cultures. The pictures (magnification x 200) are representative of the respective conditions. Cyclosporin A (CSA, $30 \mu \mathrm{M})$ was used as a positive control to induce lipid accumulation, as recommended by LipidTOX ${ }^{\mathrm{TM}}$ manufacturer. *Significantly different from control HepaRG cells $(\mathrm{P}<0.05)$. B. Determination of cellular triglycerides with a colorimetric assay. 
Results are means \pm SEM for 4 independent cultures. *Significantly different from control HepaRG cells $(\mathrm{P}<0.05)$. C. mRNA expression of APOA4, PLIN2 and PLIN3. Expression of TBP was used as reference. Results are means \pm SEM for 3 independent cultures. *Significantly different from control HepaRG cells $(\mathrm{P}<0.05)$. 
A.
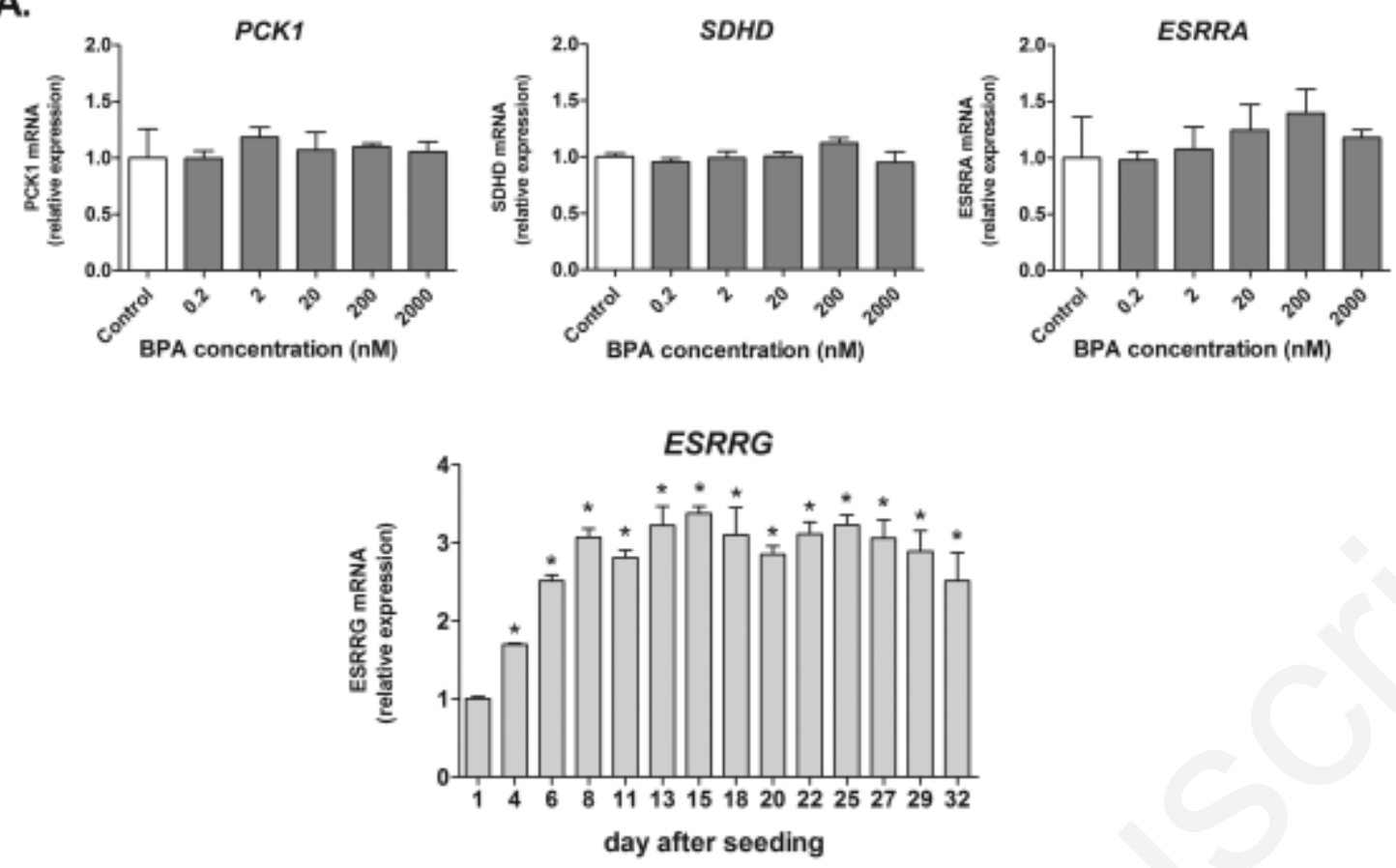

B.
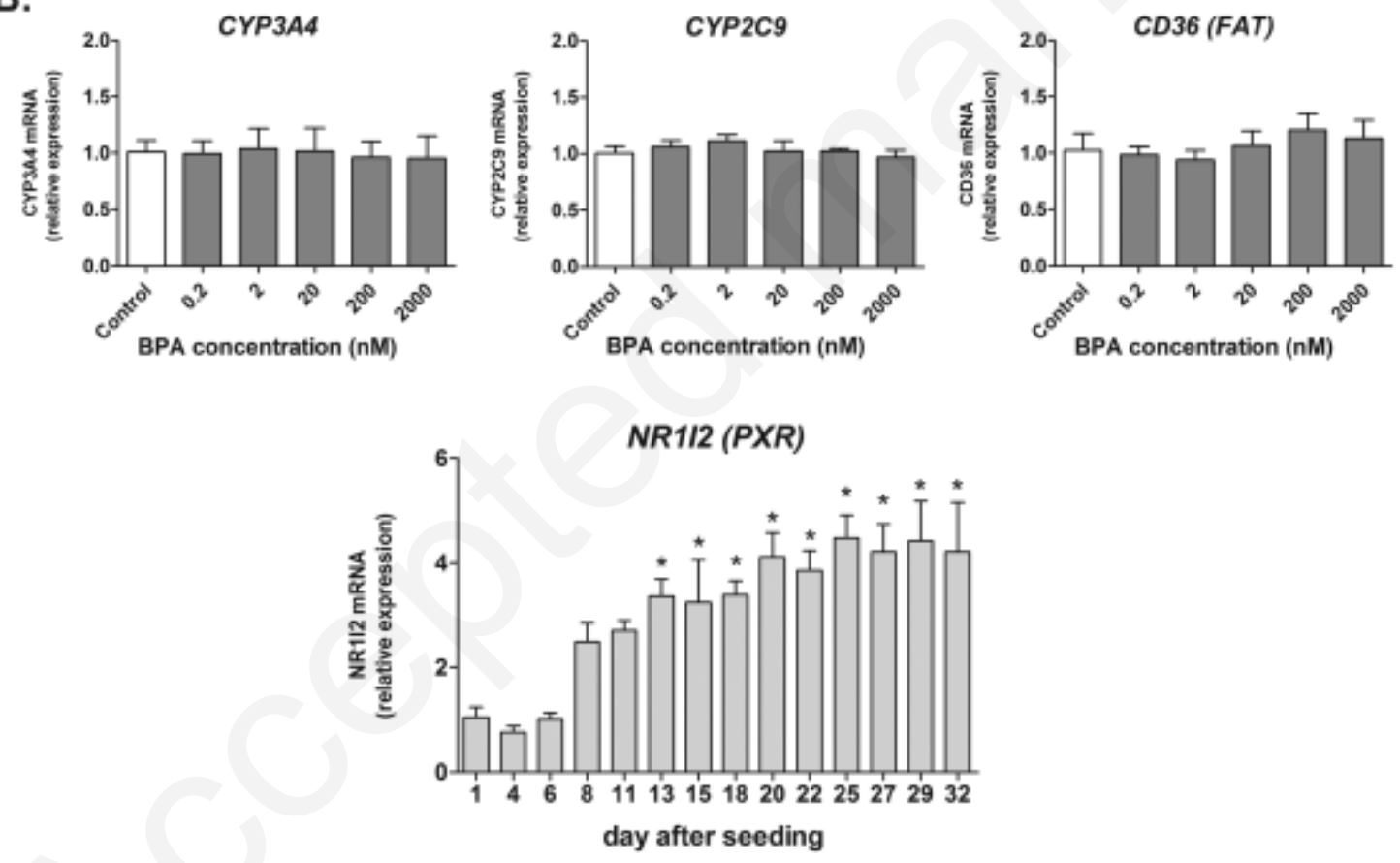

Figure 6. Effects of BPA in HepaRG cells on the expression of known targets of ERR $\gamma(\mathrm{ESRRG})$ and PXR (NR112) and kinetics of expression of these nuclear receptors over a 32-day period of cell culture after seeding. A. Expression of 3 different ESRRG target genes and kinetics of ESSRG expression. Results are means \pm SEM for 3 independent cultures. *Significantly different from HepaRG cells at day 1 after seeding $(\mathrm{P}<0.05)$. B. Expression of 3 different PXR target genes and kinetics of PXR 
expression. Results are means \pm SEM for 3 independent cultures. *Significantly different from HepaRG cells at day 1 after seeding $(\mathrm{P}<0.05)$. 